Article

\title{
Enhancement of Strength and Hot Workability of AZX312 Magnesium Alloy by Disintegrated Melt Deposition (DMD) Processing in Contrast to Permanent Mold Casting
}

\author{
Kamineni Pitcheswara Rao ${ }^{1, *}$ (D) , Kalidass Suresh ${ }^{1,+}$, \\ Yellapregada Venkata Rama Krishna Prasad ${ }^{2}$, Norbert Hort ${ }^{3, *}$ and Manoj Gupta ${ }^{4}$ \\ 1 Department of Mechanical and Biomedical Engineering, City University of Hong Kong, Tat Chee Avenue, \\ Kowloon, Hong Kong 999077, China; ksureshphy@buc.edu.in \\ 2 Independent Researcher, (Formerly with City University of Hong Kong), No. 2/B, Vinayaka Nagar, Hebbal, \\ Bengaluru 560024, India; prasad_yvrk@hotmail.com \\ 3 Magnesium Innovation Centre, Helmholtz Zentrum Geesthacht, Max-Planck-Strasse 1, \\ Geesthacht 21502, Germany \\ 4 Department of Mechanical Engineering, National University of Singapore, 9 Engineering Drive 1, \\ Singapore 117575, Singapore; mpegm@nus.edu.sg \\ * Correspondence: mekprao@cityu.edu.hk (K.P.R.); norbert.hort@hzg.de (N.H.); \\ Tel.: +852-3442-8409 (K.P.R.); Fax: +852-3442-0172 (K.P.R.) \\ † Current address: Department of Physics, Bharathiar University, Coimbatore 641046, India
}

Received: 12 May 2018; Accepted: 7 June 2018; Published: 8 June 2018

\begin{abstract}
AZX312 (AZ31-2Ca) magnesium alloy, with starting conditions of as-cast (AC), casthomogenized $(\mathrm{CH})$, and disintegrated melt deposition (DMD), is examined in terms of its compressive strength and hot working behavior to establish the relative merits and limitations of these processing routes. Processing maps are developed in the temperature range of $300-500{ }^{\circ} \mathrm{C}$ and strain rate range of $0.0003-10 \mathrm{~s}^{-1}$, and mechanisms of hot deformation are established based on microstructures, tensile ductility, and activation parameters. The alloy in $\mathrm{AC}$ and $\mathrm{CH}$ conditions has a large grain size with intermetallic phases at the grain boundaries and in the matrix. In DMD processed alloy, the grain size is very small and the phases are refined and distributed uniformly. The compressive strength is significantly improved by DMD processing, which is attributed to the grain refinement. The processing maps for $\mathrm{AC}$ and $\mathrm{CH}$ conditions are similar, exhibiting only a single workability domain, while the DMD processed alloy exhibited three domains that enhanced workability. The additional workability domain at higher strain rates is an advantage in designing forming processes that facilitates faster production, while the fine grain size produced by a finishing operation in the lower temperature domain will improve the mechanical properties of the product.
\end{abstract}

Keywords: Mg-Zn-Ca alloy; compressive strength; hot working; processing map; microstructure; kinetic analysis

\section{Introduction}

Due to their light weight, magnesium alloys are attractive as structural components in auto and aerospace industries [1], and Mg-3Al-1Zn (AZ31) has been investigated extensively [2-5] in view of its commercial popularity. However, its high temperature creep strength is found inadequate for several applications and the methods for improving this are being explored. The addition of hard particles, introduced either externally by dispersion [6-9] or produced internally by alloying with elements, 
such as $\mathrm{Ca}$, is being considered [10-12] for this purpose. Calcium does not have a high solid solubility in $\mathrm{Mg}$ at room temperature in view of its larger (23\%) atomic diameter than that of $\mathrm{Mg}$, but forms complex intermetallic particles with $\mathrm{Mg}$ and $\mathrm{Al}$, like $(\mathrm{Mg}, \mathrm{Al})_{2} \mathrm{Ca}$ or $\mathrm{CaMgZn}$, which get distributed in the microstructure [12]. The addition of Ca to AZ31 alloy refines the grain size and results in a homogeneous microstructure after forging the cast alloy, both of which increase the tensile strength and ductility $[10,11]$. The Ca content has a significant influence on the strength, elongation, and hot rolling characteristics [13]. The strength is not significantly improved in alloys with less than $1 \% \mathrm{Ca}$, whereas higher $\mathrm{Ca}$ content reduces the ductility and requires higher hot-rolling temperatures. The $\mathrm{Ca}$ addition to AZ31-RE and Mg-Ce-Mn-Zn alloys [14] refines the grain size and improves the tensile and creep properties.

The use of newer material synthesis techniques are being considered for alloy preparation, with a view to achieving chemical homogeneity and uniform particle distribution, particularly in concentrated alloys. In recent years, the technique called disintegrated melt deposition (DMD) is found to be attractive [15-17].

In this technique, the alloy melt is disintegrated into droplets in an inert atmosphere and deposited onto a metallic substrate and the deposited billets are further processed by hot extrusion. In the conventional method of processing $\mathrm{Mg}$ alloys with high alloying content, namely the casting process, the microstructures have problems due to chemical segregation, dendrite formation, and coarse distribution of the intermetallic phases and these have highly detrimental effects on its strength and workability.

The aim of the present investigation is to evaluate the strength and hot working behavior of AZ31 alloy with $2 \%$ Ca produced by two different processing routes: (1) The conventional permanent mold casting, and (2) DMD processing, and correlate them with the microstructure produced by the individual process. This study will identify the relative benefits and limitations of the two processes from the view point of component properties and manufacture. AZX312 (AZ31-2Ca) is chosen for this study since it is a high strength alloy that would pose problems in mechanical processing. The ultimate compressive strength of the alloy processed by the above routes is compared in the temperature range of $25-250{ }^{\circ} \mathrm{C}$, while the hot working behavior is characterized using the technique of the processing map, developed in the temperature range of $300-500{ }^{\circ} \mathrm{C}$ and a strain rate range of $0.0003-10 \mathrm{~s}^{-1}$. The principles and procedure of the developing of the processing map has been described earlier [18-20]. In this model, the material undergoing hot deformation is a non-linear dissipator of power and the strain rate sensitivity $(m)$ of flow stress is the factor that partitions the power between the deformation heat and the microstructural dissipation. The efficiency of the power dissipation through microstructural changes, compared with a linear dissipator, is given by:

$$
\eta=\frac{2 m}{m+1}
$$

The efficiency variation of power dissipation with temperature and strain rate represents a power dissipation map, which is, generally, viewed as an iso-efficiency contour map. In addition, the extremum principles of irreversible thermodynamics, as applied to continuum mechanics of large plastic flow [21], are explored to define a criterion for the onset of flow instability, given by the equation for the instability parameter:

$$
\xi(\dot{\varepsilon})=\frac{\partial \ln [m /(m+1)]}{\partial \ln \dot{\varepsilon}}+m \leq 0
$$

In Equation (2), $m$ is the strain rate sensitivity and $\dot{\varepsilon}$ is the strain rate. Superimposing this inequality criterion on the power dissipation map delineates the regimes of flow instability and gives a processing map. The map exhibits domains where the workability of a material is optimal, such as dynamic recrystallization (DRX), and regimes of flow instabilities. 


\section{Materials and Experimental Procedure}

The AZ31-2Ca magnesium alloy was prepared by melting pure $\mathrm{Al}$ and $\mathrm{Zn}$ elemental metals under a cover of $\mathrm{SF}_{6}$ - argon gas mixture and adding Ca prior to pouring. The melt was mixed and poured in a preheated permanent steel mold when the melt temperature was $720^{\circ} \mathrm{C}$. The as-cast (AC) billets had a diameter of $100 \mathrm{~mm}$ and a height of $350 \mathrm{~mm}$. The cast billet was diametrically sliced and cylindrical specimens, with $10 \mathrm{~mm}$ diameter and $15 \mathrm{~mm}$ height, were machined from the sliced disks using a wire-cut electrical discharge machine. Some of the sliced disks were homogenized $(\mathrm{CH})$ at $450{ }^{\circ} \mathrm{C}$ for $5 \mathrm{~h}$ and furnace cooled.

For disintegrated melt deposition (DMD) processing, AZ31 magnesium alloy ingots were cut into rectangular pieces and holes of a $12 \mathrm{~mm}$ diameter and $30 \mathrm{~mm}$ depth were drilled into these pieces and the required amount of calcium was filled in these holes. Primary processing involved heating the magnesium alloy pieces to $750{ }^{\circ} \mathrm{C}$ under an inert argon atmosphere in a graphite crucible and disintegrated droplets of the slurry were deposited onto a metallic substrate to obtain billets of a $40 \mathrm{~mm}$ diameter. In the secondary processing, these billets were soaked for $1 \mathrm{~h}$ at a temperature of $400{ }^{\circ} \mathrm{C}$ before hot extrusion through a die preheated to $350{ }^{\circ} \mathrm{C}$ using an extrusion ratio of $13: 1$ to produce rods of $10 \mathrm{~mm}$ diameter using colloidal graphite as a lubricant. Cylindrical specimens, with a diameter of $9.8 \mathrm{~mm}$ and a height of $15 \mathrm{~mm}$, were machined from the processed rod such that the compression axis was aligned with the extrusion direction.

To evaluate compressive strength, slow strain rate compression tests were conducted in the temperature range of $25^{\circ} \mathrm{C}$ to $250{ }^{\circ} \mathrm{C}$ (in steps of $25^{\circ} \mathrm{C}$ ) and at a strain rate of $0.0001 \mathrm{~s} \mathrm{~s}^{-1}$. Details of the hot compression test set and procedure were published earlier [22]. The specimens were tested in compression in the temperature range of $300-500{ }^{\circ} \mathrm{C}$ and the true strain rate range of $0.0003-10 \mathrm{~s}^{-1}$ on a computer-controlled servo-hydraulic test machine, which has a facility for an exponential decay of actuator speed and a clam-shell furnace. The adiabatic temperature rise occurring during the test was measured using a thermocouple with a $0.8 \mathrm{~mm}$ diameter embedded in a fine hole drilled at the mid-height of the specimen. A standard lubricant paste containing graphite powder was used as a lubricant. The specimens were deformed up to a true strain of about 1.0 and immediately quenched in water. The load-stroke data were converted into true stress-true strain curves using standard equations. The flow stress values were corrected for the adiabatic temperature rise, which was measured during each compression test, and the actual temperature was obtained. The corrected flow stress was computed by fitting smooth curves for flow stress data as a function of temperature at all relevant strain rates within the experimental points. The processing map was developed from the variations of corrected flow stress with temperature and strain rate and different strains using the procedure described earlier [19]. The specimens were prepared for metallographic examination by sectioning parallel to the compression axis, polishing the cut surface, and etching with an aqueous solution containing 3\% picric acid. Under select temperature and strain rate conditions, tensile testing was conducted on cylindrical specimens with a $5 \mathrm{~mm}$ gage diameter and $25 \mathrm{~mm}$ gage length. The fractured surfaces were examined in scanning electron microscope (SEM) to record the mode of fracture.

\section{Results and Discussion}

\subsection{Starting Microstructures}

The initial microstructure of AZ31-2Ca alloy in the as-cast (AC), cast-homogenized (CH), and DMD processed conditions are given in Figure 1a-c. The AC microstructure consists of coarse dendrites, with large volume fraction of intermetallic phases at grain boundaries and dendritic interfaces. Homogenization resulted in the refining and redistributing of the intermetallic phases in a more uniform fashion (Figure 1b) than in AC microstructure (Figure 1a). However, the grain sizes in $\mathrm{AC}$ and $\mathrm{CH}$ conditions are unchanged (Figure $1 \mathrm{a}, \mathrm{b})$ and are very large $(450 \mu \mathrm{m})$. The initial microstructure for the DMD-processed alloy (Figure 1c) has wrought features showing mechanical 
fibering along the extrusion direction and a finely recrystallized grain structure with an average grain diameter of $3 \mu \mathrm{m}$.

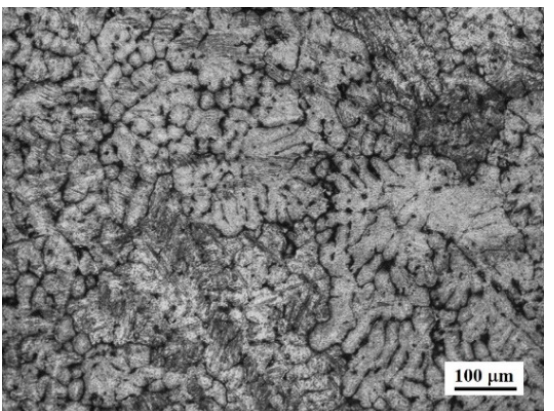

(a)

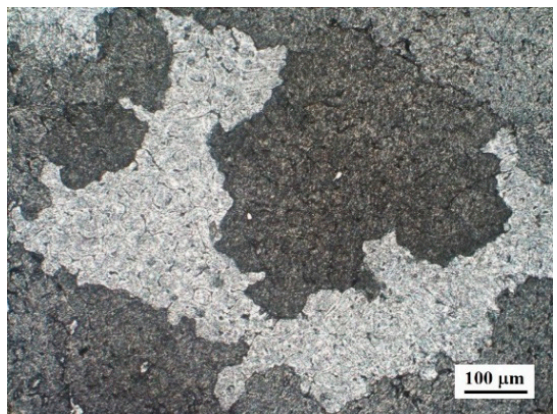

(b)

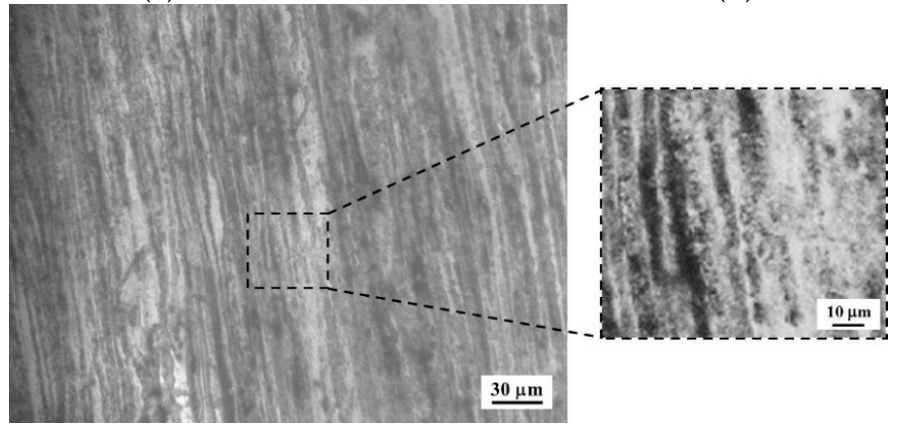

(c)

Figure 1. Optical initial microstructure of AZ31-2Ca alloy for different conditions: (a) As-cast; (b) homogenized; and (c) disintegrated melt deposition (DMD) processed-extrusion direction is vertical.

The SEM microstructure of the as-cast AZ31-2Ca alloy is shown in Figure 2a, which shows that two intermetallic phases exist: (1) $(\mathrm{Mg}, \mathrm{Al})_{2} \mathrm{Ca}$ at the grain boundaries, and (2) $\mathrm{Ca}_{2} \mathrm{Mg}_{6} \mathrm{Zn}_{3}$ in the matrix. These two phases were also present in the microstructure for $\mathrm{CH}$ material. The SEM image obtained on the DMD processed AZ31-2Ca alloy is given in Figure $2 b$, which reveals $(\mathrm{Mg}, \mathrm{Al})_{2} \mathrm{Ca}$ particles occurring along bands in the extrusion direction and distributed as particles. In addition, few $\mathrm{Al}_{8} \mathrm{Mn}_{5}$ particles are present randomly in the matrix. The phases present in this AZ31-2Ca alloy are comparable to those reported in the literature $[10,12,23,24]$. The concentration of applicable elements from SEM-EDS (scanning electron microscope-energy dispersive spectroscopy) mapping of as-cast and DMD-processed AZ31-2Ca alloy is shown in Figure 3a,b, respectively. The elements, $\mathrm{Zn}$ and Mn, are distributed uniformly in the matrix, while $\mathrm{Ca}$ and $\mathrm{Al}$ are concentrated at the grain boundaries.

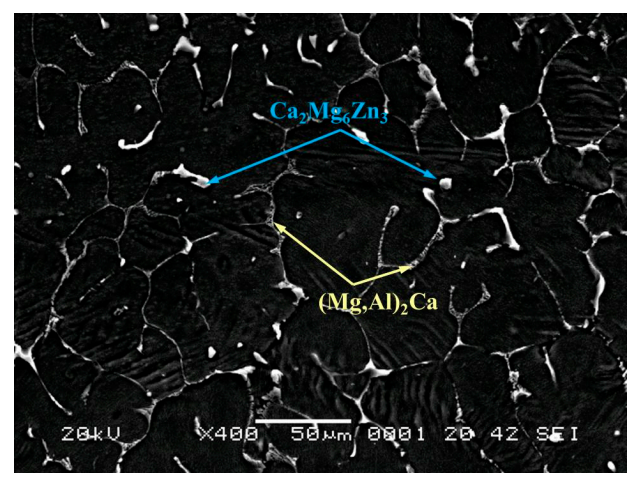

(a)

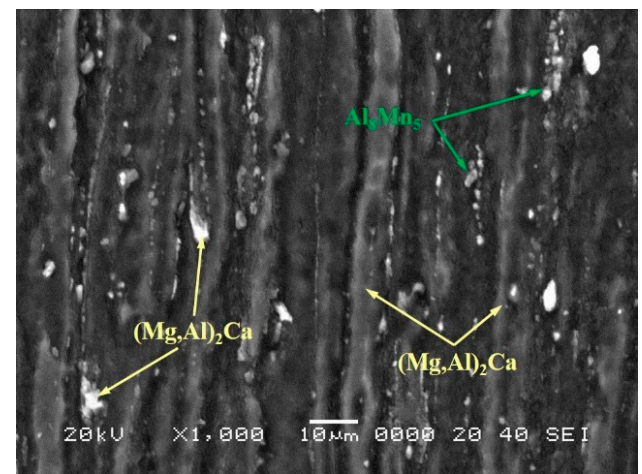

(b)

Figure 2. Scanning electron microscope (SEM) initial microstructure of AZ31-2Ca alloy for (a) as-cast and (b) DMD processed conditions exhibiting intermetallic particles. 

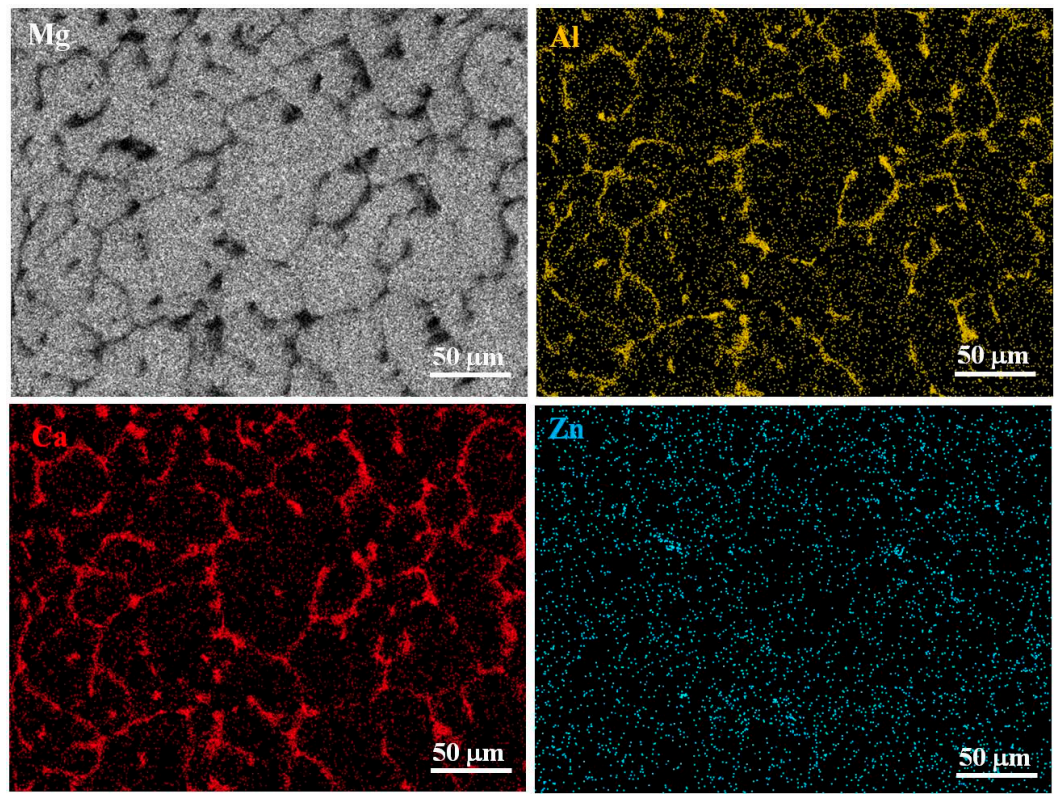

(a)

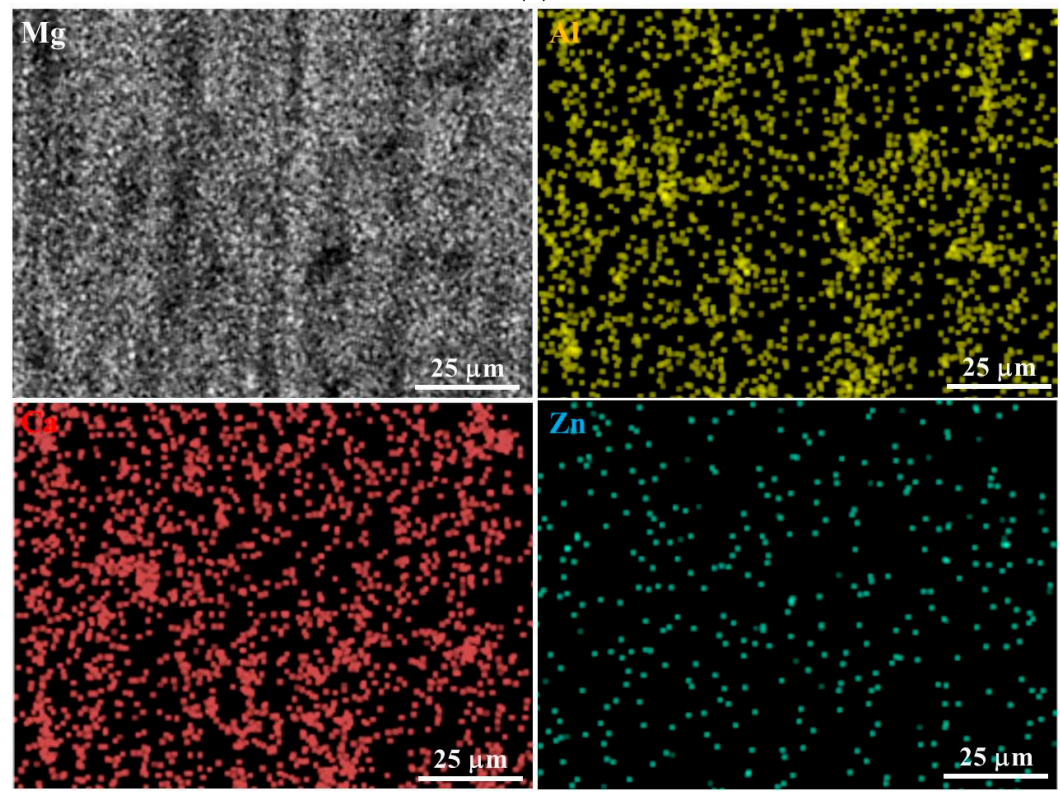

(b)

Figure 3. Scanning electron microscope-energy dispersive spectroscopy (SEM-EDS) map showing elemental distribution of AZ31-2Ca alloy for (a) as-cast and (b) DMD processed conditions.

\subsection{Ultimate Compressive Strength}

The variation of the ultimate compressive strength (UCS) of AZ31-2Ca alloy with temperature in the range of $25-250{ }^{\circ} \mathrm{C}$ at a strain rate of $0.0001 \mathrm{~s}^{-1}$ for $\mathrm{AC}, \mathrm{CH}$, and DMD-processed conditions is shown in Figure 4. The strength is slightly reduced by homogenization, which may be attributed to the redistribution of intermetallic phases away from the grain boundaries. Thus, homogenization is not helpful from a strengthening view point. In comparison, the DMD-processed alloy exhibited a significant increase in strength by as much as $55 \%$ at room temperature, which may be the direct result of substantial grain refinement. The strength of all three alloys decreases with increasing temperature and at temperatures above $175^{\circ} \mathrm{C}$ the DMD processed alloy has a lower strength than $\mathrm{AC}$ and $\mathrm{CH}$ conditions. This may be the result of the occurrence of grain boundary sliding, since the grain size is very fine $(3 \mu \mathrm{m})$ compared with that of $\mathrm{AC}$ and $\mathrm{CH}$ specimens $(450 \mu \mathrm{m})$. 


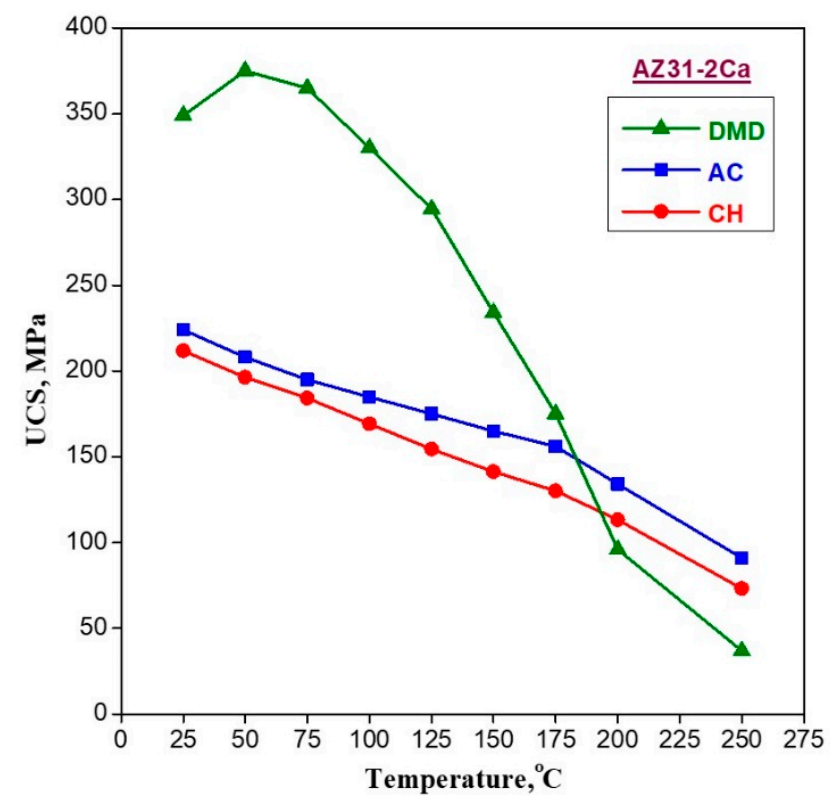

Figure 4. Ultimate compressive strength (UCS) of AZ31-2Ca alloy for DMD processed, as-cast (AC), and cast-homogenized $(\mathrm{CH})$ conditions at different temperatures.

\subsection{Stress-Strain Behaviour}

The true stress-true strain curves obtained on $\mathrm{AC}$ and $\mathrm{CH}$ specimens are compared at temperatures of $300{ }^{\circ} \mathrm{C}$ and $400{ }^{\circ} \mathrm{C}$ and at different strain rates in Figure $5 a, b$, respectively. The curves at $300{ }^{\circ} \mathrm{C}$ exhibit a steady state flow at lower strain rates and flow softening at higher strain rates, leading to shear fractures. However, the curves at $400{ }^{\circ} \mathrm{C}$ exhibit better flow, even though there is flow softening at higher strain rates. It may be noted that the stress-strain behavior is similar in $\mathrm{AC}$ and $\mathrm{CH}$ conditions.

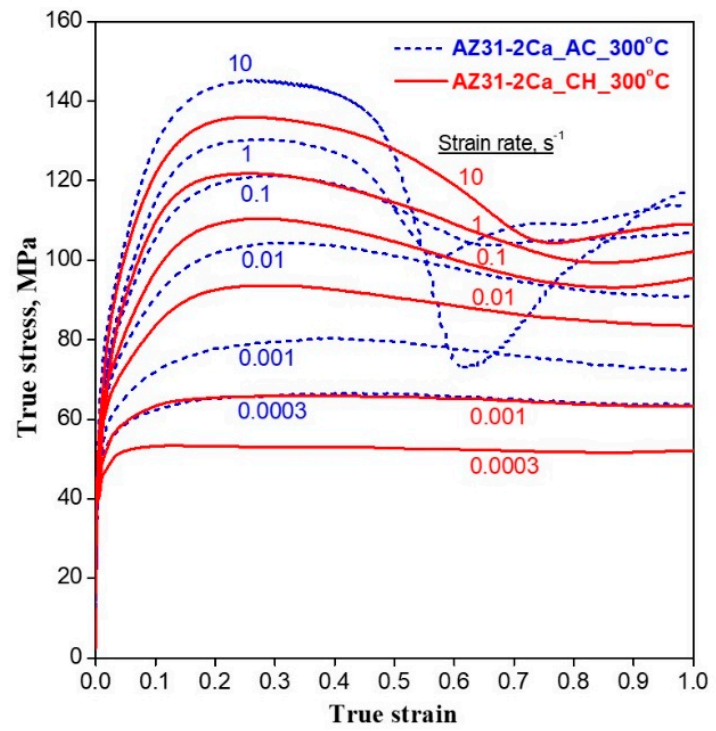

(a)

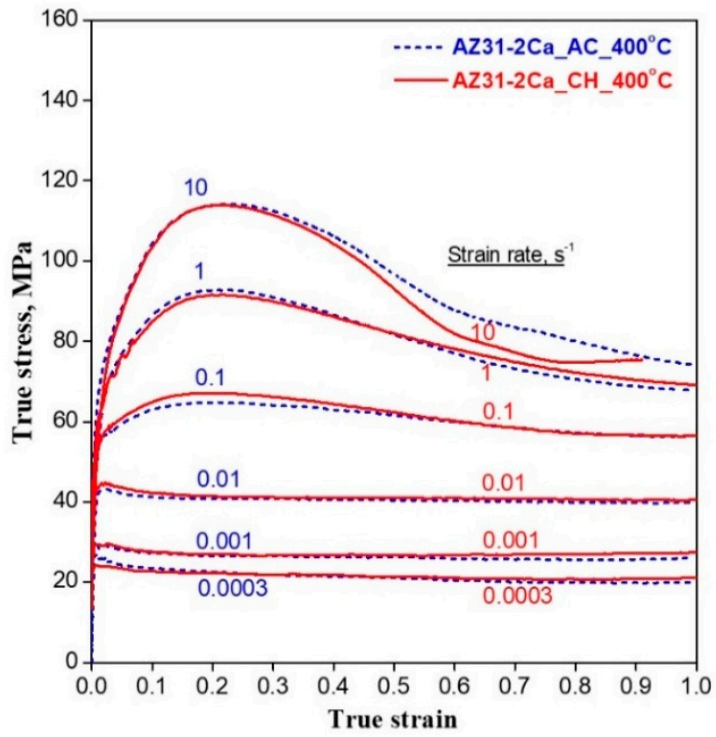

(b)

Figure 5. True stress - true strain curves obtained on as-cast (AC) and cast-homogenized $(\mathrm{CH})$ specimens at different strain rates at temperatures of (a) $300{ }^{\circ} \mathrm{C}$ and (b) $400{ }^{\circ} \mathrm{C}$. 
The true stress-true strain curves for $\mathrm{AC}$ and DMD processed conditions are compared in Figure $6 \mathrm{a}, \mathrm{b}$ for temperatures of $300{ }^{\circ} \mathrm{C}$ and $400{ }^{\circ} \mathrm{C}$, respectively. The flow stress for DMD specimens is higher at higher strain rates and lower at lower strain rates than that of the AC specimens. At $300{ }^{\circ} \mathrm{C}$, flow softening occurs at higher strain rates and leads to catastrophic shear failure at the strain rate of $10 \mathrm{~s}^{-1}$, and steady state flow is exhibited at lower strain rates. The behavior of DMD and AC specimens is similar at $400{ }^{\circ} \mathrm{C}$.

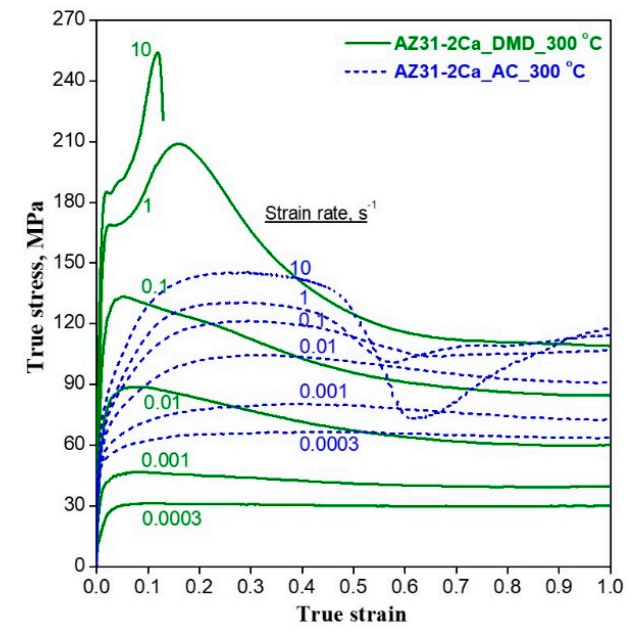

(a)

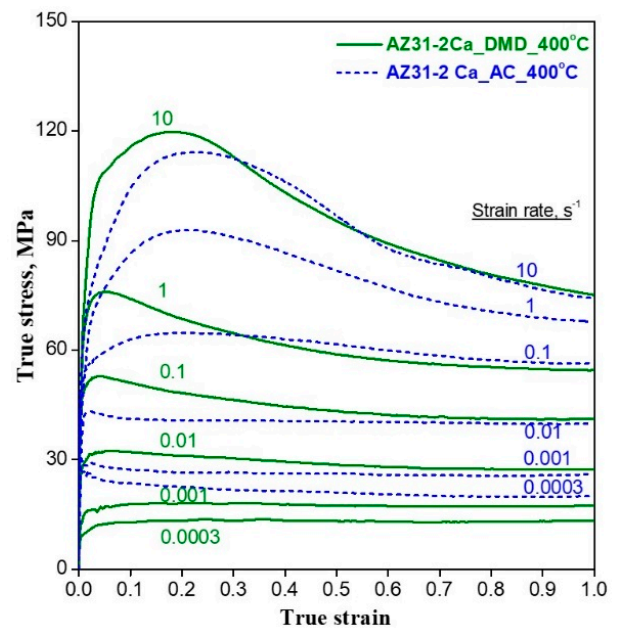

(b)

Figure 6. True stress-true strain curves obtained on DMD and AC specimens at different strain rates at temperatures of (a) $300{ }^{\circ} \mathrm{C}$ and (b) $400{ }^{\circ} \mathrm{C}$.

\subsection{Processing Maps}

\subsubsection{AC and CH Specimens}

The processing maps obtained on $\mathrm{AC}$ and $\mathrm{CH}$ specimens at a strain of 0.7 (near steady-state) are shown in Figure 7a,b. The numbers against the contours represent the efficiency of power dissipation as a percent. The map for AC specimens (Figure 7a) reveals two domains in the following temperature and strain rate ranges:

(1) $350-450{ }^{\circ} \mathrm{C}$ and $0.0003-0.05 \mathrm{~s}^{-1}$, with a peak efficiency of $38 \%$ at $450{ }^{\circ} \mathrm{C} / 0.0003 \mathrm{~s}^{-1}$.

(2) $450-500{ }^{\circ} \mathrm{C}$ and $0.03-3 \mathrm{~s}^{-1}$, with a peak efficiency of $40 \%$ at $500{ }^{\circ} \mathrm{C} / 0.1 \mathrm{~s}^{-1}$.

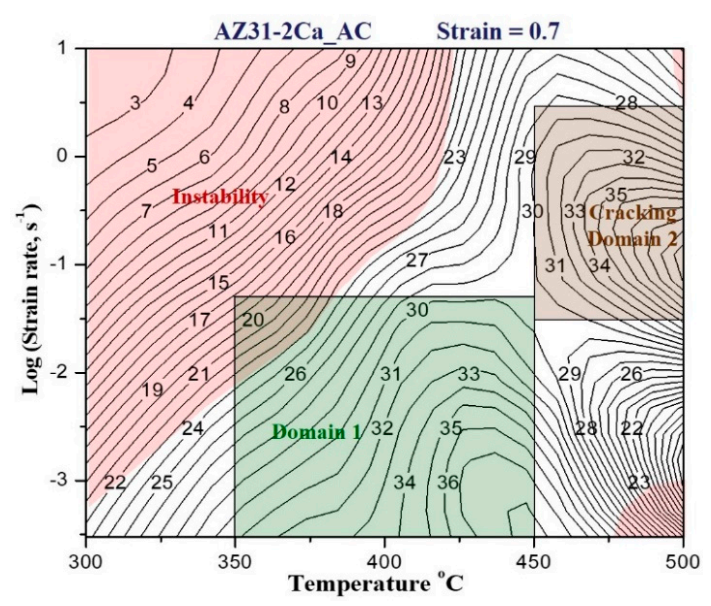

(a)

Figure 7. Cont. 


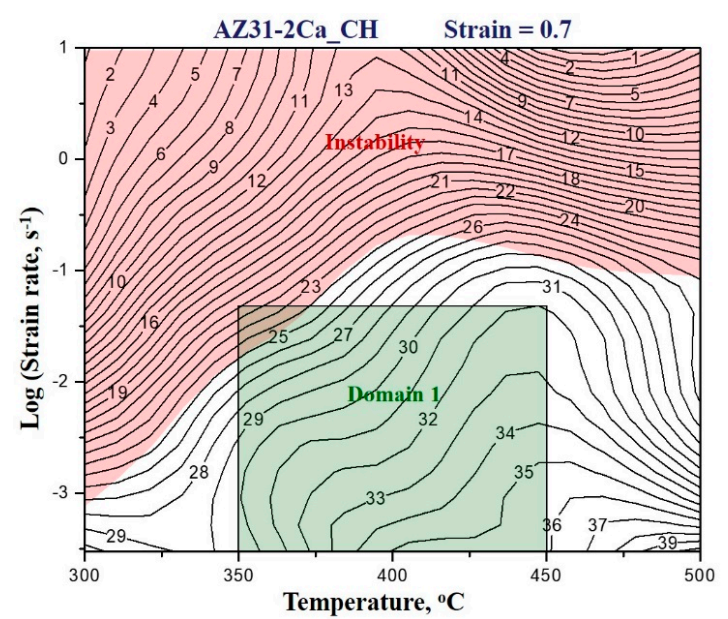

(b)

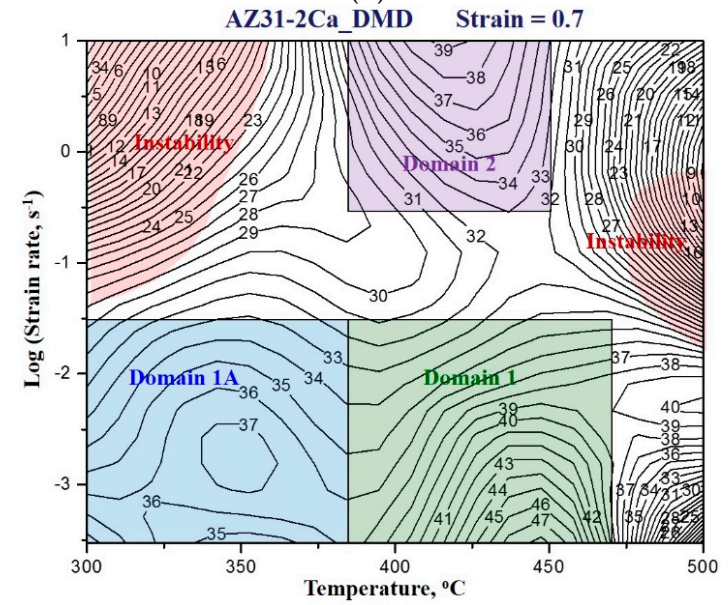

(c)

Figure 7. Processing map of AZ31-2Ca at a strain of 0.7: (a) As-cast; (b) homogenized; and (c) DMD processed conditions. The contour numbers denote the efficiency of power dissipation as a percent.

The specimens deformed in Domain \#2 have disintegrated due to intense grain boundary cracking. A wide regime of flow instability is present in both maps at higher strain rates and a part of this instability is replaced by intergranular cracking at higher temperatures in AC material. The microstructural manifestation of flow instability is in the form of flow localization bands, which are shown by arrows in Figure 8a.

The processing map for $\mathrm{CH}$ specimens (Figure $7 \mathrm{~b}$ ) exhibits a single domain in the following temperature and strain rate ranges: $350-450{ }^{\circ} \mathrm{C}$ and $0.0003-0.05 \mathrm{~s}^{-1}$, with a peak efficiency of $36 \%$ at $450{ }^{\circ} \mathrm{C} / 0.0003 \mathrm{~s}^{-1}$. The cracking domain observed in the AC specimens (Figure 7a) is not present in the $\mathrm{CH}$ map. This is to be expected since the volume of the intermetallic phase at the grain boundary is considerably reduced by homogenization (Figure 1b). A comparison of the maps indicates that the hot working characteristics are, essentially, similar for $\mathrm{AC}$ and $\mathrm{CH}$ conditions in as far as the workability domain is concerned.

The microstructures on the specimens deformed at a strain rate of $0.0003 \mathrm{~s}^{-1}$ (Domain \#1) are shown in Figure 9a,b which correspond to temperatures of $400^{\circ} \mathrm{C}$ and $450^{\circ} \mathrm{C}$. These show that DRX is nucleated at grain boundaries at $400{ }^{\circ} \mathrm{C}$ (Figure 9a) and is nearly complete at $450{ }^{\circ} \mathrm{C}$ (Figure $9 \mathrm{~b}$ ), since the initial as-cast grain size of $450 \mu \mathrm{m}$ is very much refined. The respective grain sizes in Figure $9 \mathrm{a}, \mathrm{b}$ are 10 and $30 \mu \mathrm{m}$. 


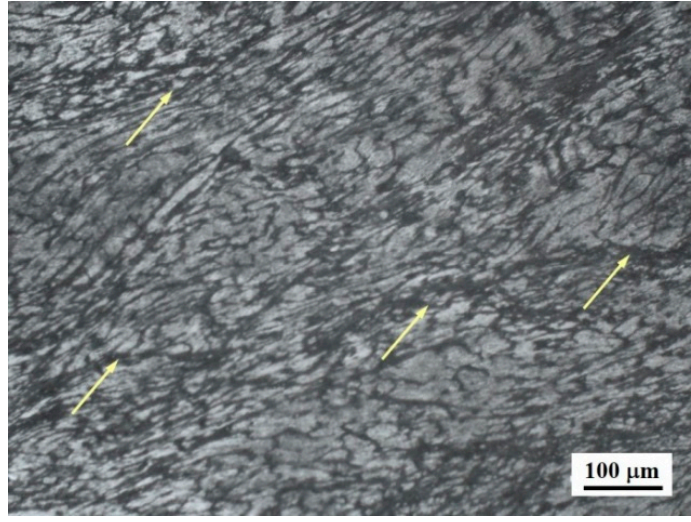

(a)

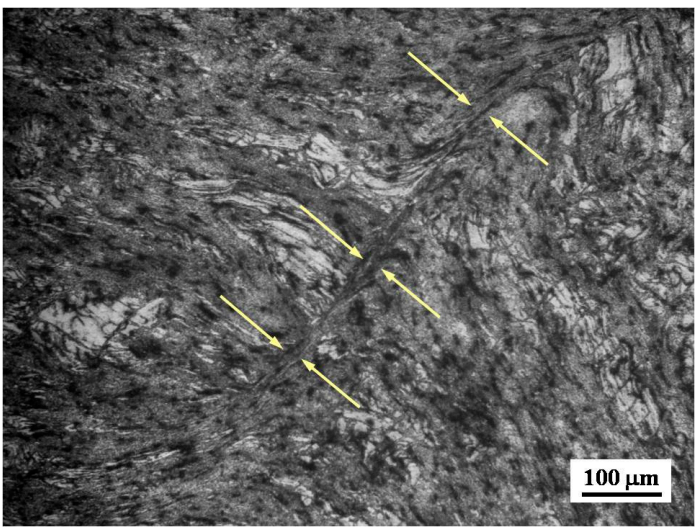

(b)

Figure 8. Deformed microstructures obtained in the instability regime of AZ31-2Ca alloy at (a) as-cast alloy at $300{ }^{\circ} \mathrm{C} / 10 \mathrm{~s}^{-1}$, exhibiting flow localization; and (b) DMD processed at $300{ }^{\circ} \mathrm{C} / 1 \mathrm{~s}^{-1}$, showing adiabatic shear band.

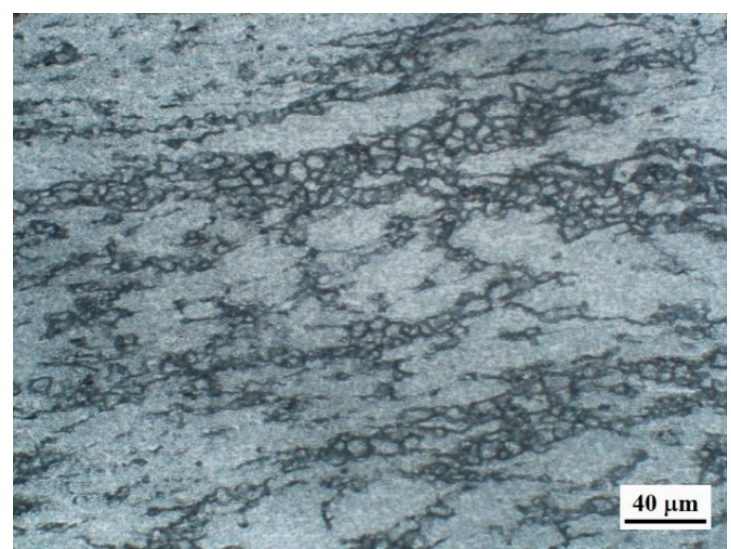

(a)

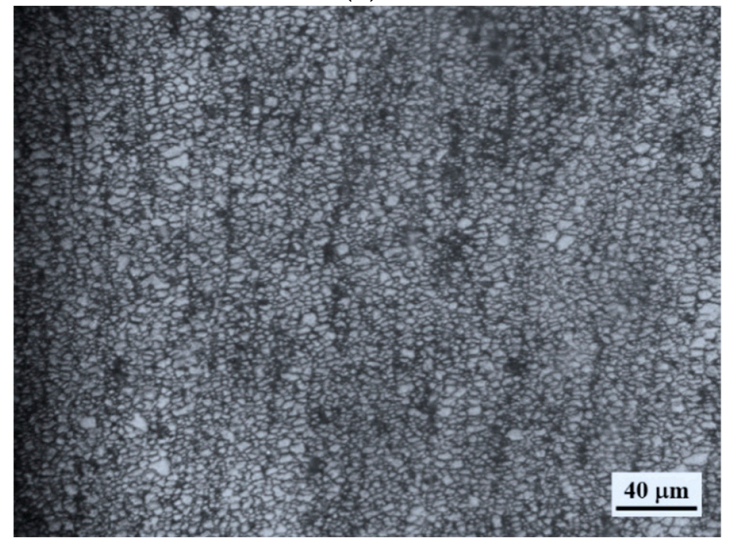

(c)

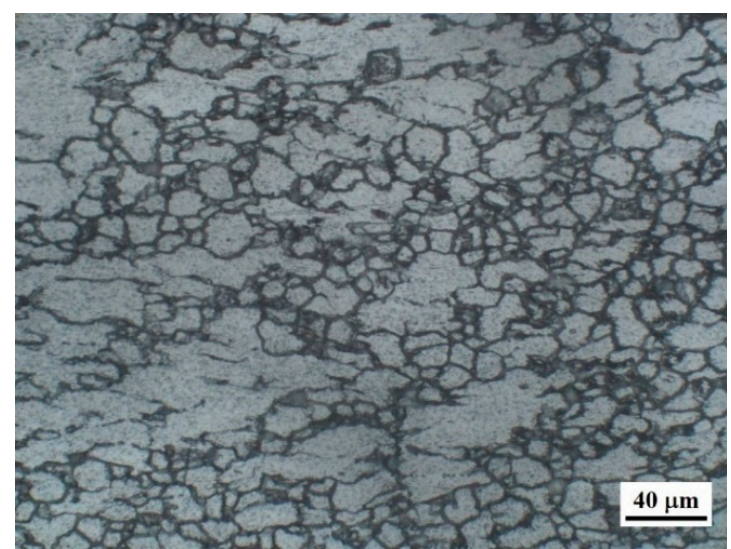

(b)

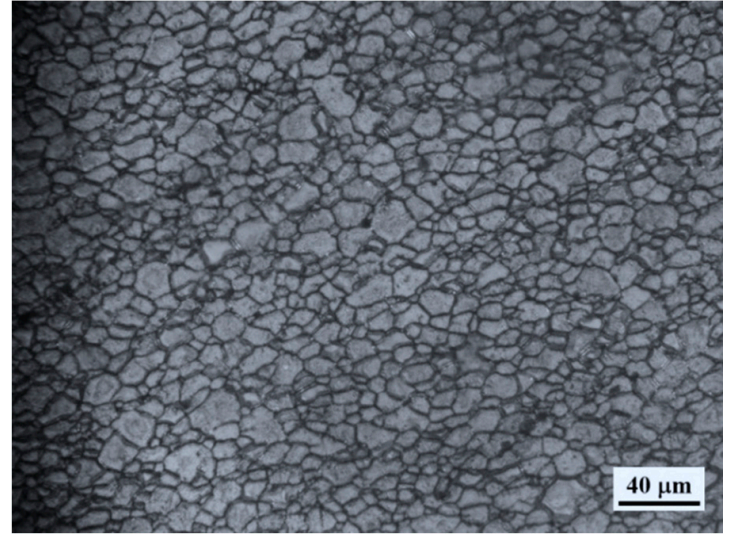

(d)

Figure 9. Dynamic recrystallized (DRX) microstructures obtained on as-cast AZ31-2Ca alloy in Domain $\# 1$ at (a) $400{ }^{\circ} \mathrm{C} / 0.0003 \mathrm{~s}^{-1}$; (b) $450{ }^{\circ} \mathrm{C} / 0.0003 \mathrm{~s}^{-1}$; and on DMD processed alloy in Domain \#1A at (c) $350{ }^{\circ} \mathrm{C} / 0.0003 \mathrm{~s}^{-1}$ and in Domain \#1 at (d) $450{ }^{\circ} \mathrm{C} / 0.0003 \mathrm{~s}^{-1}$.

Tensile total elongations have been measured on specimens deformed under conditions within Domain \#1 and these were $25 \%$ at $350{ }^{\circ} \mathrm{C} / 0.001 \mathrm{~s}^{-1}$ and $33 \%$ at $400{ }^{\circ} \mathrm{C} / 0.01 \mathrm{~s}^{-1}$. The engineering stress-engineering strain curves obtained in tension for $\mathrm{AC}$ and DMD processed conditions are shown in Figure 10. 


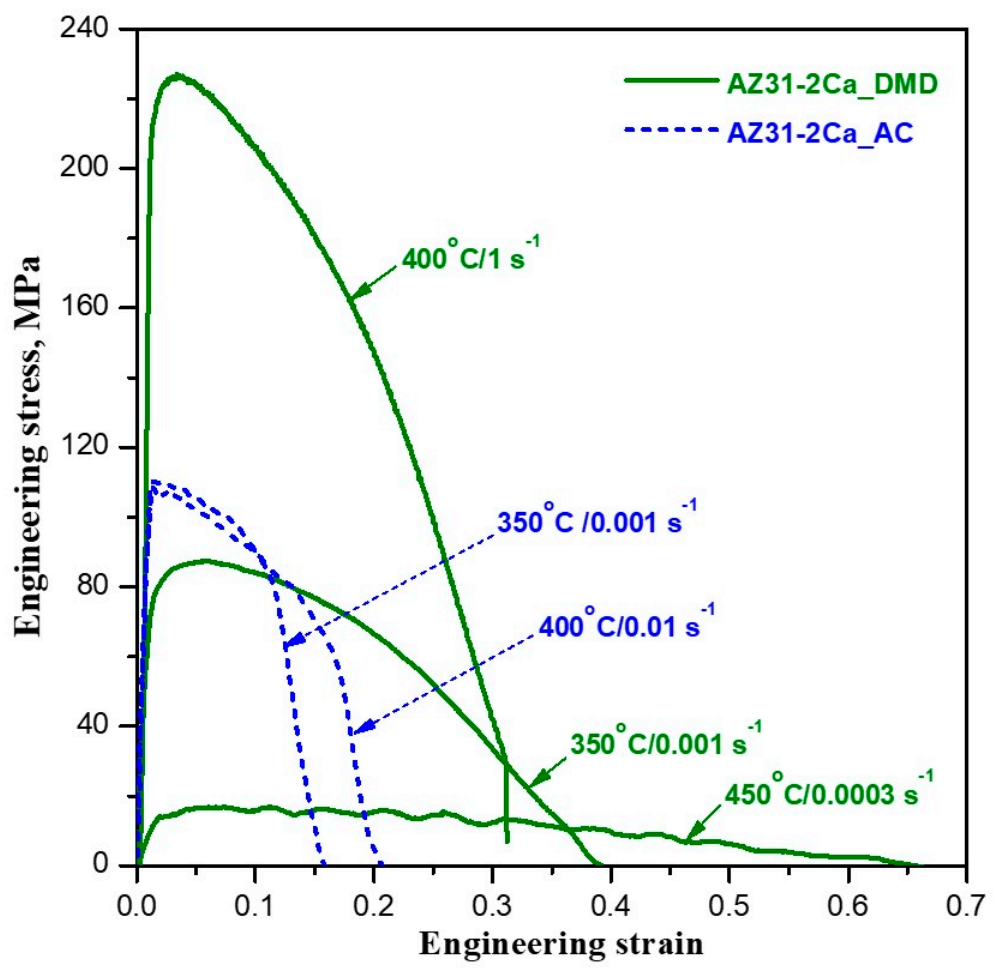

Figure 10. Engineering stress-Engineering strain curves obtained in tension on AZ31-2Ca alloy in AC and DMD conditions in different domains of processing maps.

The SEM fractographs taken on the tensile fractured surfaces are shown in Figure 11a,b, respectively, which exhibit dimple features typical of ductile fracture. Thus, the workability in this domain is good and is caused by the occurrence of DRX. At $500^{\circ} \mathrm{C}$ and at all strain rates, the AC alloy exhibits intercrystalline fracture (Figure 11c,d), presumably caused by incipient melting at grain boundaries, since the actual temperature of the specimen may increase beyond $500{ }^{\circ} \mathrm{C}$ due to deformation heat, particularly at higher strain rates. Homogenization was not helpful in eliminating this effect, but made it less catastrophic.

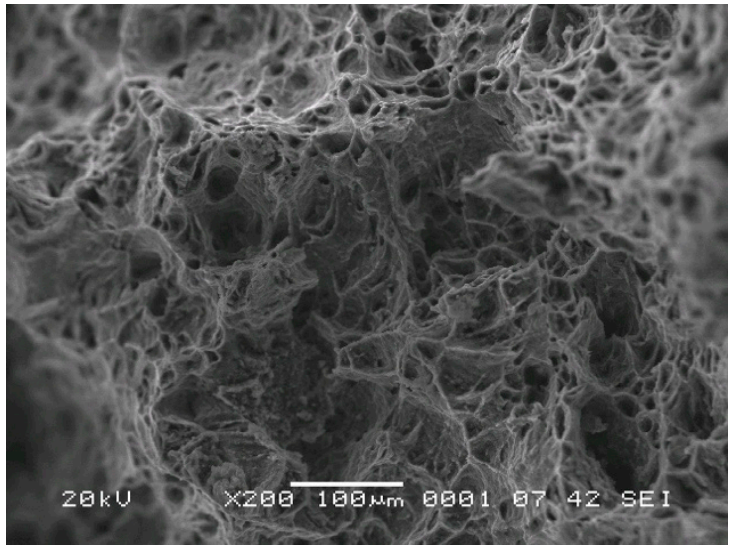

(a)

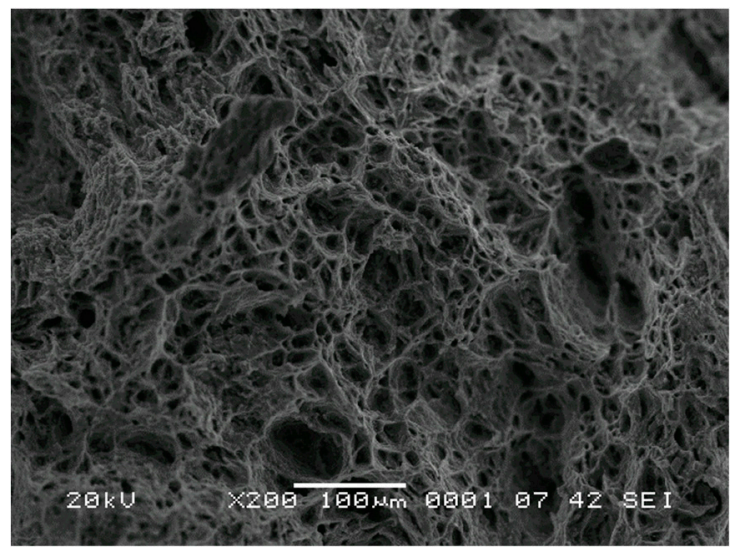

(b)

Figure 11. Cont. 


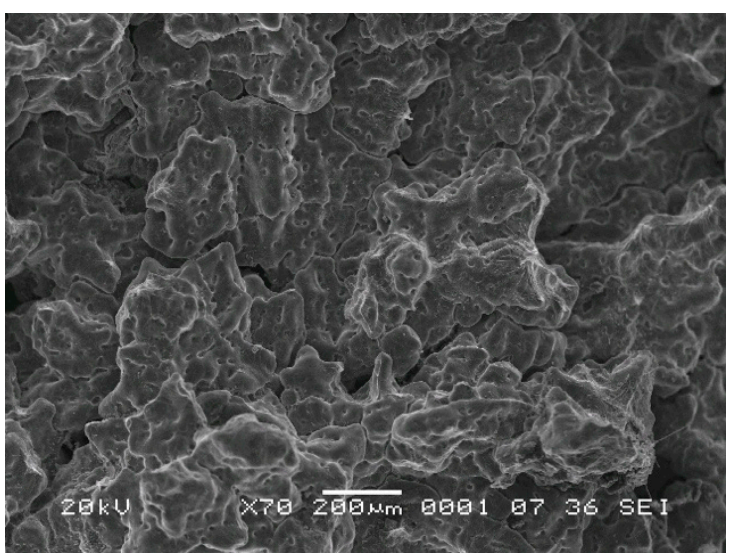

(c)

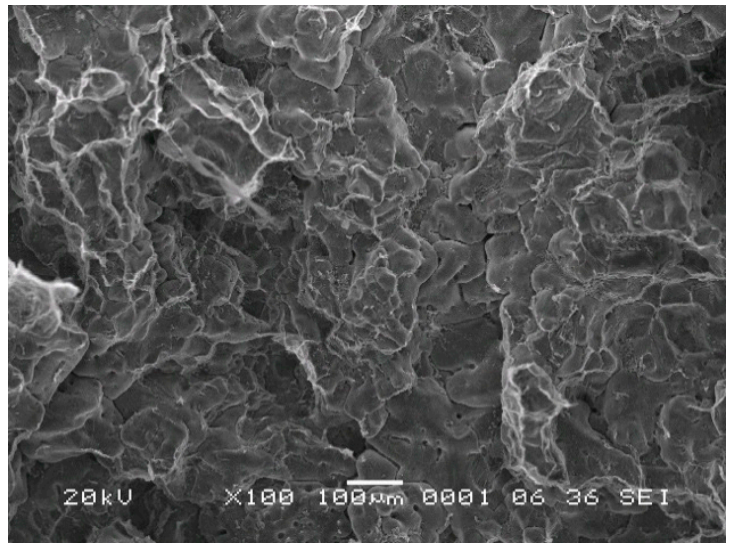

(d)

Figure 11. The fracture surface of an as-cast AZ31-2Ca alloy specimen tested in uniaxial tension at Domain \#1 area of (a) $350{ }^{\circ} \mathrm{C} / 0.001 \mathrm{~s}^{-1}$; and (b) $400{ }^{\circ} \mathrm{C} / 0.01 \mathrm{~s}^{-1}$, showing ductile fracture, and a specimen tested at Domain \#2 and the nearby region of (c) $500{ }^{\circ} \mathrm{C} / 0.1 \mathrm{~s}^{-1}$ and (d) $500{ }^{\circ} \mathrm{C} / 0.001 \mathrm{~s}^{-1}$, showing intercrystalline fracture.

DRX in Domain \#1 occurs at temperatures higher than $400{ }^{\circ} \mathrm{C}$ where second order pyramidal slip $\{11-22\}<11-23>$ causes plastic flow and the recovery mechanism that nucleates DRX is cross-slip, since many intersecting slip systems are available and the stacking fault energy on this second order pyramidal system is estimated to be high $\left(173 \mathrm{~mJ} \mathrm{~m}^{-2}\right)$ [25]. The apparent activation energy for this process may be estimated with the help of the kinetic rate equation relating the steady-state flow stress $(\sigma)$ to the temperature $(T)$ and strain rate $(\varepsilon)$, given by [26]:

$$
\dot{\varepsilon}=A \sigma^{n} \exp [-Q / R T]
$$

where $n, Q$, and $R$, are the stress exponent, apparent activation energy, and gas constant, respectively, and $\mathrm{A}$ is a constant. The pre-exponential factor is related to the dislocation density, area slipped, burgers vector, and atomic frequency [26]. A plot of flow stress versus strain rate at different temperatures is shown in Figure 12 and the Arrhenius plot showing the natural logarithm of flow stress, normalized with respect to the shear modulus versus inverse of absolute temperature, is shown in Figure 13. The values of activation parameters obtained are $n=5.13$ and $Q=228 \mathrm{~kJ} / \mathrm{mole}$ from these plots, which are also shown in Table 1. The corresponding values obtained on $\mathrm{CH}$ specimens are 4.64 and $198 \mathrm{~kJ} / \mathrm{mole}$, which are not significantly different from those obtained in the AC condition. This reiterates the earlier findings that homogenization did not cause perceptible change in the hot working behavior. The apparent activation energy is much higher than that for lattice self-diffusion (135 k/mole) [26], which is a consequence of the large back-stress generated by the intermetallic particles in the microstructure, which must be overcome before cross-slip can occur. Thus, in Domain \#1 of the processing map for $\mathrm{AC}$ and $\mathrm{CH}, \mathrm{DRX}$ occurs by second order pyramidal slip, along with cross-slip for recovery. At temperatures higher than $400{ }^{\circ} \mathrm{C}$, other non-basal slip systems, like prismatic and first order pyramidal type, would also be contributing to the deformation, and cross-slip on these systems causes recovery. However, the second-order pyramidal system would be dominating due to the availability of a large number of slip systems and high stacking fault energy $\left(173 \mathrm{~mJ} \mathrm{~m}^{-2}\right)$ [25]. 


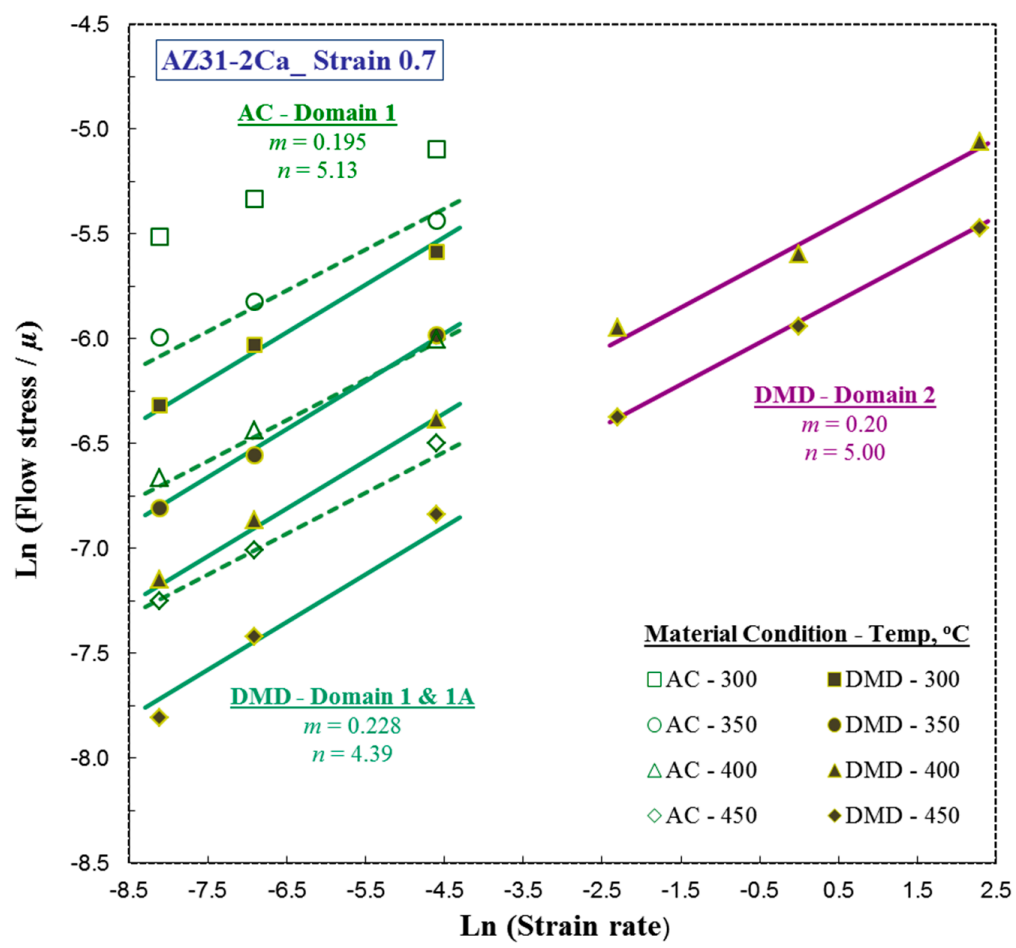

Figure 12. Variation of flow stress with strain rate at a strain of 0.7 in the various domains of DMD processed against as-cast in Domain \#1 of AZ31-2Ca alloy.

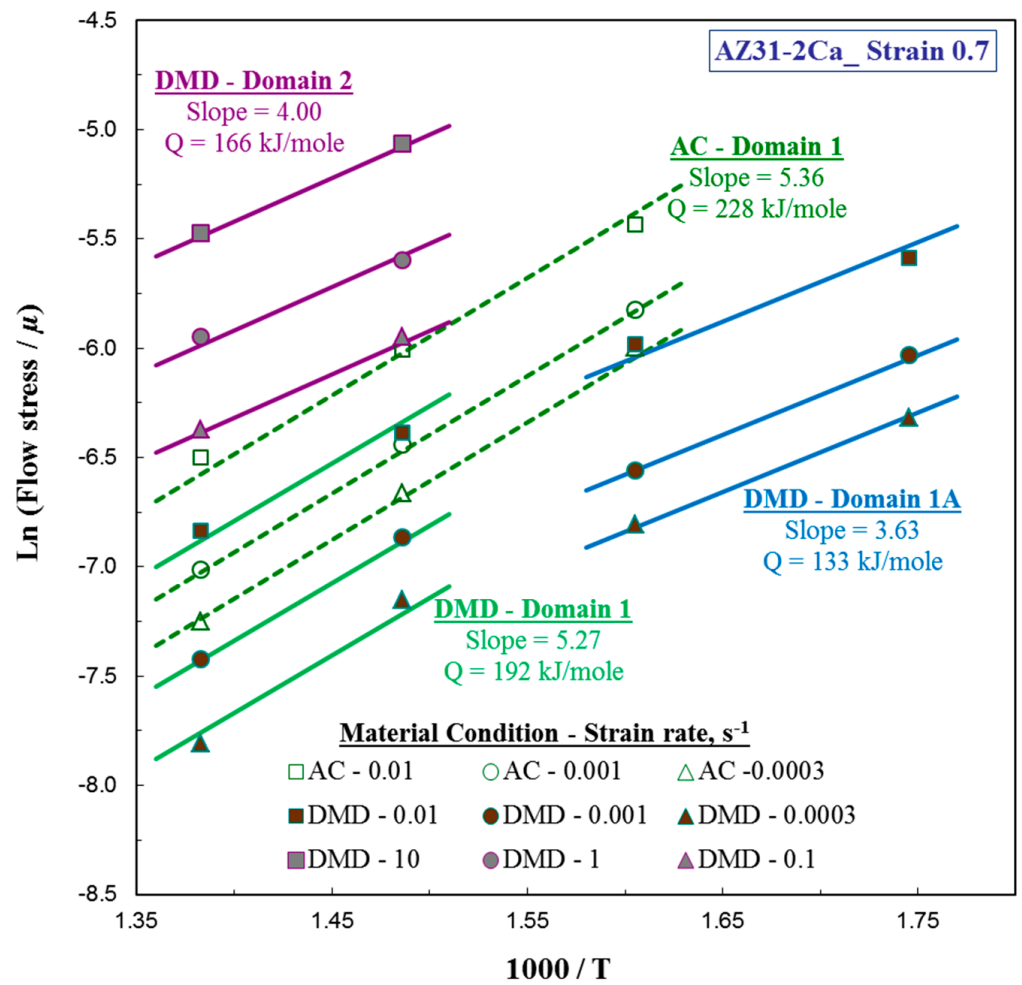

Figure 13. Arrhenius plots obtained on AZ31-2Ca in the processing domains of DMD processed against as-cast alloy. 
Table 1. Activation parameters in stable domains of processing maps for as-cast, homogenized, and DMD processed AZX312 magnesium alloy.

\begin{tabular}{|c|c|c|c|c|c|c|c|c|c|}
\hline \multirow{2}{*}{ Domain } & \multicolumn{3}{|c|}{ As-Cast } & \multicolumn{3}{|c|}{ Cast-Homogenized } & \multicolumn{3}{|c|}{ DMD Processed } \\
\hline & $T / \dot{\varepsilon}$ at Peak $\eta$ & $n$ & $Q, \mathrm{~kJ} / \mathrm{mole}$ & $T / \dot{\varepsilon}$ at Peak $\eta$ & $n$ & $Q, \mathrm{~kJ} / \mathrm{mole}$ & $T / \dot{\varepsilon}$ at Peak $\eta$ & $n$ & $Q, \mathrm{~kJ} / \mathrm{mole}$ \\
\hline$\# 1$ & $450^{\circ} \mathrm{C} / 0.0003 \mathrm{~s}^{-1}$ & 5.13 & 228 & $450{ }^{\circ} \mathrm{C} / 0.0003 \mathrm{~s}^{-1}$ & 4.64 & 198 & $450{ }^{\circ} \mathrm{C} / 0.0003 \mathrm{~s}^{-1}$ & 4.39 & 192 \\
\hline$\# 1 \mathrm{~A}$ & - & - & - & - & - & - & $350{ }^{\circ} \mathrm{C} / 0.002 \mathrm{~s}^{-1}$ & 4.39 & 133 \\
\hline$\# 2$ & $500{ }^{\circ} \mathrm{C} / 0.1 \mathrm{~s}^{-1}$ & Grain $\mathrm{b}$ & dary cracking & - & - & - & $420^{\circ} \mathrm{C} / 10 \mathrm{~s}^{-1}$ & 5.00 & 166 \\
\hline
\end{tabular}

\subsubsection{DMD Processed Specimens}

The processing map obtained on DMD processed specimens at a strain of 0.7 is shown in Figure 7c, which exhibits the following domains in the temperature and strain rate ranges given by:

(\#1A) $300-385^{\circ} \mathrm{C}$ and $0.0003-0.03 \mathrm{~s}^{-1}$, with a peak efficiency of $37 \%$ at $350{ }^{\circ} \mathrm{C} / 0.003 \mathrm{~s}^{-1}$,

(\#1) $\quad 385-470{ }^{\circ} \mathrm{C}$ and $0.0003-0.03 \mathrm{~s}^{-1}$, with a peak efficiency of $48 \%$ at $450{ }^{\circ} \mathrm{C} / 0.0003 \mathrm{~s}^{-1}$,

(\#2) $\quad 385-450{ }^{\circ} \mathrm{C}$ and $0.3-10 \mathrm{~s}^{-1}$, with a $38 \%$ peak efficiency of at $420{ }^{\circ} \mathrm{C} / 10 \mathrm{~s}^{-1}$.

Flow instability regimes have occurred at $>0.1 \mathrm{~s}^{-1}$ and in the temperature range of $300-350{ }^{\circ} \mathrm{C}$, as well as at $475-500{ }^{\circ} \mathrm{C}$ and $0.01-1 \mathrm{~s}^{-1}$. The microstructural manifestation of the instability at lower temperatures is in the form of flow localization and adiabatic shear band formation, as shown in Figure $8 \mathrm{~b}$, while at higher temperatures $\left(500^{\circ} \mathrm{C}\right)$ and higher strain rates $\left(>0.01 \mathrm{~s}^{-1}\right)$ the specimens have disintegrated due to intercrystalline cracking.

The microstructures of specimens deformed under peak efficiency conditions in Domains \#1A $\left(350{ }^{\circ} \mathrm{C} / 0.0003 \mathrm{~s}^{-1}\right)$ and Domain $\# 1\left(450{ }^{\circ} \mathrm{C} / 0.0003 \mathrm{~s}^{-1}\right)$ are shown in Figure $9 \mathrm{c}$, d, which show DRX has occurred in both these domains. The respective grain sizes are 5 and $15 \mu \mathrm{m}$. The microstructure of the specimen deformed at peak efficiency conditions $\left(400{ }^{\circ} \mathrm{C} / 10 \mathrm{~s}^{-1}\right)$ in Domain \#2 is shown in Figure 14a, which shows that DRX has occurred in this domain also. This may be compared with that obtained on the AC alloy deformed under similar conditions (Figure 14b), which exhibits static recrystallization in the localized shear bands, formed due to flow instability.

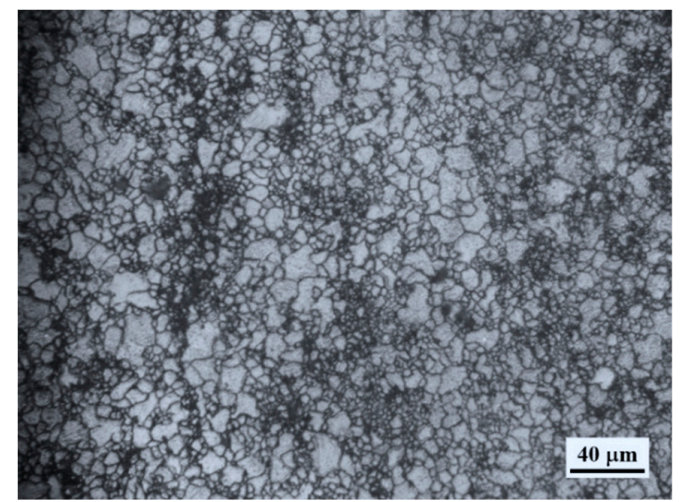

(a)

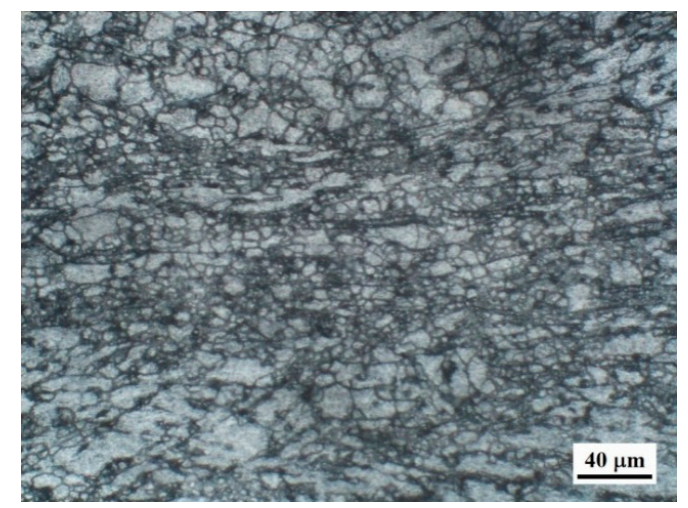

(b)

Figure 14. Deformed microstructures obtained for AZ31-2Ca alloy at $400{ }^{\circ} \mathrm{C} / 10 \mathrm{~s}^{-1}$ (a) in DMD processed (Domain \#2), showing DRX; and (b) in AC alloy, exhibiting static recrystallization occuring in localized bands.

The ductility of the DMD processed alloy at peak efficiency conditions in the three domains described above is measured in tension. The engineering stress-engineering strain curves obtained in tension are shown in Figure 10. The total elongation is $43 \%$ in Domain 1A, $75 \%$ in Domain \#1, and 35\% in Domain \#2. SEM fractographs taken on the fractured surfaces of the tensile specimens are shown in Figure 15 and all indicate ductile fracture, as expected for DRX mechanisms in all the 
three domains, making them suitable for hot working the DMD processed alloy. Domain \#2 may be preferred, in particular, in view of the higher strain rates it offers for viable manufacturing.

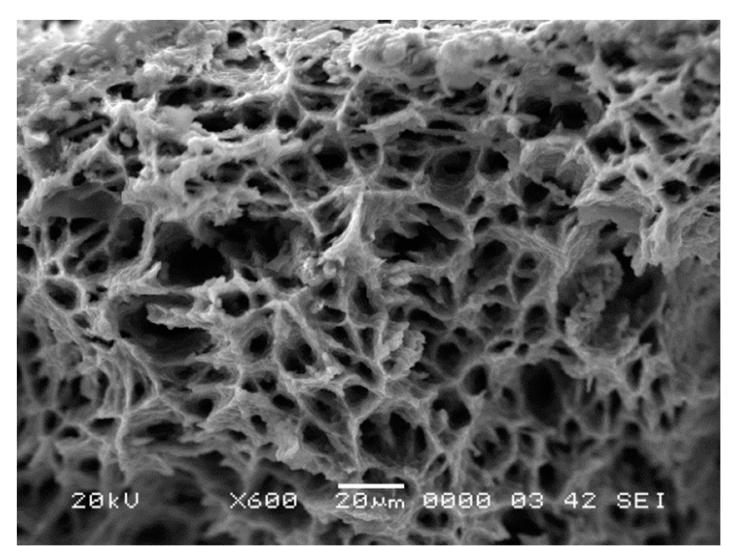

(a)

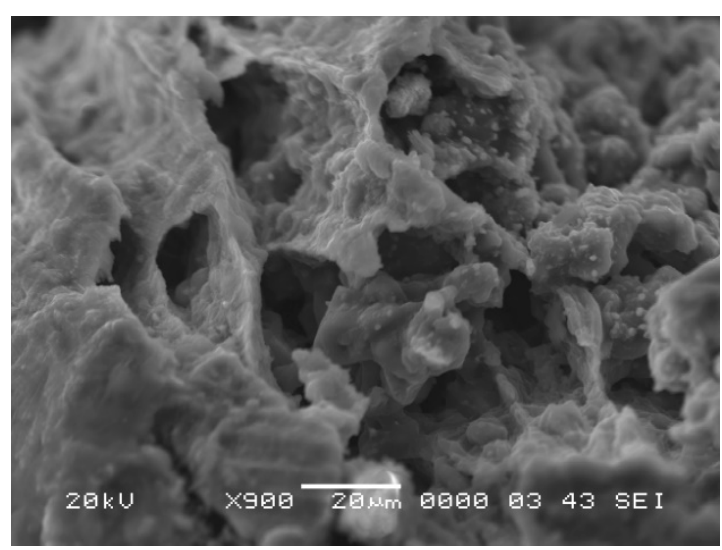

(b)

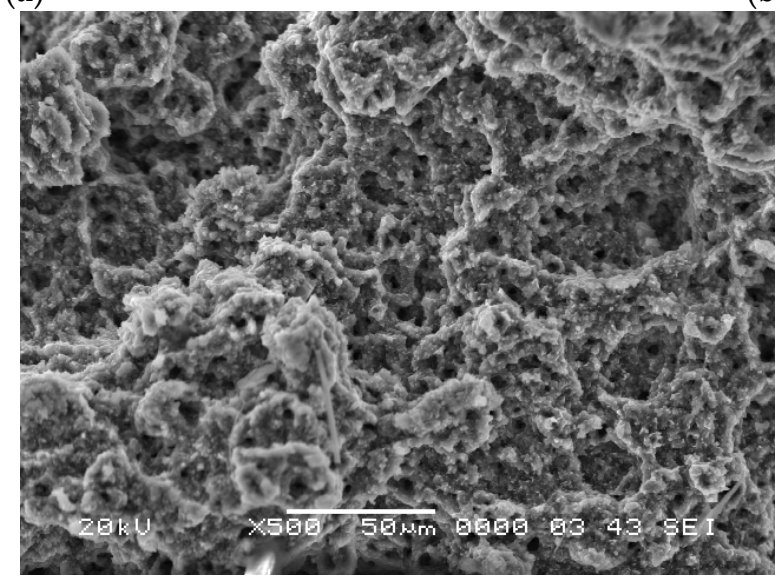

(c)

Figure 15. Fracture surface of DMD processed AZ31-2Ca alloy specimen tested in uniaxial tension in (a) $350{ }^{\circ} \mathrm{C} / 0.001 \mathrm{~s}^{-1}$ (Domain \#1A); (b) $450{ }^{\circ} \mathrm{C} / 0.0003 \mathrm{~s}^{-1}$ (Domain \#1); and (c) $400{ }^{\circ} \mathrm{C} / 1 \mathrm{~s}^{-1}$ (Domain \#2), showing ductile fracture.

The mechanism occurring in these domains may be evaluated with the help of kinetic analysis in the temperature and strain rate ranges restricted to each of the domains. Domain \#1A in the DMD map occurs at temperatures $<385^{\circ} \mathrm{C}$, where slip on prismatic slip system $\{10-10\}<11-20>$ dominates, although first order pyramidal slip may also contribute. The recovery mechanism that nucleates DRX when prismatic slip occurs is the climb of edge dislocations, which is controlled by lattice self-diffusion. This is favored to occur in this domain since the strain rates are slow. The activation analysis plots are done based on the rate equation (Equation (3)) and are shown in Figures 12 and 13, and the values are given in Table 1 . The value of the stress exponent, $n=4.39$, and that of the apparent activation energy, $Q$, is $133 \mathrm{~kJ} /$ mole. The apparent activation energy is close to that for self-diffusion in $\mathrm{Mg}$ (135 kJ/mole) [27], confirming that lattice diffusion controlled climb is the mechanism in Domain \#1A.

Domain \#1 in the DMD map occurs at temperatures $>385{ }^{\circ} \mathrm{C}$ and the efficiency peak is at $450{ }^{\circ} \mathrm{C} / 0.0003 \mathrm{~s}^{-1}$. At these higher temperatures, second order pyramidal slip $\{11-22\}<11-23>$ occurs and the recovery mechanism that nucleates DRX will be cross-slip of screw dislocations, since this slip system offers multiple intersecting planes and a higher stacking fault energy $\left(173 \mathrm{~mJ} \mathrm{~m}^{-2}\right)$ [25]. The apparent activation energy obtained from data in this domain is $192 \mathrm{~kJ} / \mathrm{mole}$, which is much higher than that for self-diffusion in Mg. The apparent activation energy is close to that obtained in 
Domain \#1 of AC and CH specimens (Table 1), suggesting that the same mechanism, namely second order pyramidal slip and cross-slip, controls DRX in all of them.

Domain \#2 in the DMD map is at temperatures $>385{ }^{\circ} \mathrm{C}$, but is at higher strain rates than Domains \#1A or \#1. As in the case of Domain \#1, DRX occurs by slip on the second order system \{11-22\} $<11-23>$. However, the recovery mechanism of cross-slip, being a thermally activated one, is restricted at higher strain rates. Alternate mechanisms requiring lower thermal activation energy may take over and the most common one is the grain boundary self-diffusion, the activation energy for which is about $95 \mathrm{~kJ} / \mathrm{mole}$ [27]. Due to limited data in this domain, accurate estimates of apparent activation energy could not be obtained but rough estimates indicate values of $n=5.00$ and $Q=166 \mathrm{~kJ} / \mathrm{mole}$. This value is higher than for grain boundary self-diffusion, but is lower than that estimated in Domains \#1A and \#1. The apparent activation energy being higher than that for grain boundary self-diffusion may be attributed to the presence of large back-stress caused by the fine distribution of intermetallic particles in the matrix, which will have to be overcome before slip can occur. Recovery by grain boundary self-diffusion occurs readily at higher strain rates since it is faster than lattice self-diffusion. The finer grain size present in the DMD processed alloy promotes this mechanism since a large grain boundary area is available. Thus, the most likely mechanism controlling DRX in this domain is grain-boundary self-diffusion. The finer grain sizes present in the DMD processed alloy promote this mechanism since a large grain boundary area is available. It also explains why Domain \#2 is not present in the maps for $\mathrm{AC}$ and $\mathrm{CH}$ specimens, which have a very large grain size.

\subsection{Implications in Process Design for AZX312 Alloy}

In the as-cast condition, AZX312 alloy has a limited hot workability due to a narrow available temperature range and slower strain rates. In addition, flow instability and intercrystalline cracking restricts the processing window even further. Commonly, one of the processing steps recommended for improving the workability is homogenization. In AZX312 alloy, the results have clearly shown that neither the ultimate compressive strength nor the hot workability has improved in any significant manner. It may be concluded that the homogenization step may be eliminated in designing hot working processes for this alloy. On the other hand, DMD processing has yielded attractive results: The ultimate compressive strength has improved significantly and options of multiple workability windows became available in the processing map and the flow instability regime is reduced. DMD processed alloy has shown two significant changes in the hot working behavior compared to AC: (1) A window (Domain \#2) for hot working the alloy became available at higher strain rates, which may be used for faster production as required in manufacturing; and (2) A lower temperature window (Domain \#1A) for finishing operations so that finer grain size is achieved in the product.

\section{Conclusions}

The compressive strength and hot working behavior of AZX312 (AZ31-2Ca) magnesium alloy in as-cast (AC), cast-homogenized (CH), and disintegrated melt deposition (DMD) processed conditions have been evaluated, with a view to bring out the relative merits and limitation of these processing routes. Processing maps have been developed in the temperature range of $300-500{ }^{\circ} \mathrm{C}$ and the strain rate range of $0.0003-10 \mathrm{~s}^{-1}$, and mechanisms of hot deformation have been established. The following conclusions are drawn from this investigation:

(1) The alloy in the $\mathrm{AC}$ and $\mathrm{CH}$ condition has a large grain size, with high volume fraction of intermetallic phases- $(\mathrm{Mg}, \mathrm{Al})_{2} \mathrm{Ca}$ and $\mathrm{Ca}_{2} \mathrm{Mg}_{6} \mathrm{Zn}_{3}$ - present at the grain boundaries and in the matrix. In DMD processed alloy, the grain size is very fine and the phases are refined and distributed uniformly.

(2) The ultimate compressive strength is slightly lowered by homogenization and is significantly improved by DMD processing, which is attributed to the grain refinement occurring in DMD.

(3) The processing maps for $\mathrm{AC}$ and $\mathrm{CH}$ specimens are similar and exhibited a workability domain in the temperature range of $350-450{ }^{\circ} \mathrm{C}$ and the strain rate range of $0.0003-0.05 \mathrm{~s}^{-1}$. On the basis 
of microstructure, tensile ductility, and activation analysis, this domain is interpreted to represent DRX occurring by second order pyramidal slip and cross-slip.

(4) The processing map for DMD processed alloy exhibited three workability windows in the temperature and strain rate ranges: (1A) $300-385^{\circ} \mathrm{C}$ and $0.0003-0.03 \mathrm{~s}^{-1}$, (1) $385-470{ }^{\circ} \mathrm{C}$ and $0.0003-0.03 \mathrm{~s}^{-1}$, and (2) $385-450{ }^{\circ} \mathrm{C}$ and $0.3-10 \mathrm{~s}^{-1}$. DRX occurs in all these and is controlled by prismatic slip + climb in Domain \#1A, second order pyramidal slip in Domains \#1 and \#2 with cross-slip and grain boundary self-diffusion as rate-controlling mechanisms, respectively.

(5) While Domain \#1 is common to all the three conditions, Domains \#1A and \#2 are new in the map for DMD processed alloy, indicating an enhancement in workability by DMD.

(6) The availability of additional workability domains in the DMD map has implications in the design of hot working processes, since the higher strain rates offered by Domain \#2 will lead to faster production rates and the fine grain sizes produced by finishing operations in Domain \#1A will improve the mechanical properties of the product.

(7) Homogenization is not beneficial to, either, improve the strength or the hot workability of the alloy and may be eliminated in designing hot working process schedules.

Author Contributions: K.P.R. has performed the analysis of the data, kinetic analysis and writing the paper; K.S. has performed the experimental work, generating the processing maps and microstructural work; Y.V.R.K.P. has contributed on the aspects related to the processing map and writing the paper, N.H. has developed and provided the cast alloy and its microstructure; M.G. has contributed towards developing the alloy using disintegrated melt deposition and extrusion process.

Acknowledgments: This work described in this paper was supported by a grant from the supported by a Strategic Research Grant (Project \#7002704) from the City University of Hong Kong and a General Research Fund (GRF Project \#114811) from the Research Grants Council of Hong Kong SAR, China.

Conflicts of Interest: The authors declare no conflict of interest.

\section{References}

1. Kainer, K.U.; Dieringa, H.; Dietzel, W.; Hort, N.; Blawert, C. The use of magnesium alloys: Past, present and future. In Magnesium Technology in Global Age; Pekguleryuz, M.O., Mackenzie, L.W.F., Eds.; Canadian Institute of Mining, Metallurgy and Petroleum: Montreal, QC, Canada, 2006; pp. 3-19.

2. Vespa, G.; Mackenzie, L.W.F.; Verma, R.; Zarandi, F.; Essadiqi, E.; Yue, S. The influence of the as-hot rolled microstructure on the elevated temperature mechanical properties of magnesium AZ31 sheet. Mater. Sci. Eng. A 2008, 487, 243-250. [CrossRef]

3. Jain, A.; Duygulu, O.; Brown, D.W.; Tome, C.N.; Agnew, S.R. Grain size effects on the tensile properties and deformation mechanisms of a magnesium alloy AZ31B sheet. Mater. Sci. Eng. A 2008, 486, 545-555. [CrossRef]

4. Ulacia, I.; Salisbury, C.P.; Hurtado, I.; Worswick, M.J. Tensile characterization and constitutive modeling of AZ31B magnesium alloy sheet over wide range of strain rates and temperatures. J. Mater. Process. Technol. 2011, 211, 830-839. [CrossRef]

5. Yang, X.; Miura, H.; Sakai, T. Structural development at severely high strain in AZ31 magnesium alloy processed by cold forging and subsequent annealing. Mater. Des. 2013, 44, 573-579. [CrossRef]

6. Habibnejad-Korayem, M.; Mahmudi, R.; Poole, W.J. Enhanced properties of Mg-based nano-composites reinforced with $\mathrm{Al}_{2} \mathrm{O}_{3}$ nanoparticles. Mater. Sci. Eng. A 2009, 519, 198-203. [CrossRef]

7. Paramsothy, M.; Chan, J.; Kwok, R.; Gupta, M. Enhanced mechanical response of hybrid alloy AZ31/AZ91 based on the addition of $\mathrm{Si}_{3} \mathrm{~N}_{4}$ nanoparticles. Mater. Sci. Eng. A 2011, 528, 6545-6551. [CrossRef]

8. Paramsothy, M.; Hassan, S.F.; Srikanth, N.; Gupta, M. Enhancing tensile/compressive response of magnesium alloy AZ31 by integrating with $\mathrm{Al}_{2} \mathrm{O}_{3}$ nanoparticles. Mater. Sci. Eng. A 2009, 527, 162-168. [CrossRef]

9. Zhong, T.; Rao, K.P.; Prasad, Y.V.R.K.; Zhao, F.; Gupta, M. Hot deformation mechanisms, microstructure and texture evolution in extruded AZ31-nano-alumina composite. Mater. Sci. Eng. A 2014, 589, 41-49. [CrossRef]

10. Kim, J.H.; Kang, N.E.; Yim, C.D.; Kim, B.K. Effect of calcium content on the microstructural evolution and mechanical properties of wrought Mg-3Al-1Zn alloy. Mater. Sci. Eng. A 2009, 525, 18-29. [CrossRef] 
11. Masoudpanah, S.M.; Mahmudi, R. Effects of rare-earth elements and Ca additions on the microstructure and mechanical properties of AZ31 magnesium alloy processed by ECAP. Mater. Sci. Eng. A 2009, 526, 22-30. [CrossRef]

12. Suresh, K.; Rao, K.P.; Prasad, Y.V.R.K.; Hort, N.; Kainer, K.U. Effect of calcium addition on the hot working behavior of as-cast AZ31 magnesium alloy. Mater. Sci. Eng. A 2013, 588, 272-279. [CrossRef]

13. Yim, C.D.; You, B.S.; Lee, J.S.; Kim, W.C. Optimization of hot rolling process of gravity cast AZ31-xCa ( $\mathrm{x}=0 \sim 2.0$ mass\%) alloys. Mater. Trans. 2004, 45, 3018-3022. [CrossRef]

14. Yang, M.; Zhang, J.; Guo, T. Effects of Ca addition on as-cast microstructure and mechanical properties of Mg-3Ce-1.2Mn-1Zn (wt.\%) magnesium alloy. Mater. Des. 2013, 52, 274-283. [CrossRef]

15. Hassan, S.F.; Gupta, M. Development of nano- $\mathrm{Y}_{2} \mathrm{O}_{3}$ containing magnesium nanocomposites using solidification processing. J. Alloys Compd. 2007, 429, 176-183. [CrossRef]

16. Nguyen, Q.B.; Gupta, M. Improving compressive strength and oxidation resistance of AZ31B magnesium alloy by addition of nano- $\mathrm{Al}_{2} \mathrm{O}_{3}$ particulates and Ca. J. Compos. Mater. 2010, 44, 883-896. [CrossRef]

17. Nguyen, Q.B.; Gupta, M. Enhancing mechanical response of $\mathrm{AZ31B}$ using $\mathrm{Cu}+$ nano- $\mathrm{Al}_{2} \mathrm{O}_{3}$ addition. Mater. Sci. Eng. A 2010, 527, 1411-1416. [CrossRef]

18. Prasad, Y.V.R.K.; Rao, K.P.; Sasidhara, S. Hot Working Guide: A Compendium of Processing Maps, 2nd ed.; ASM International: Materials Park, OH, USA, 2015; ISBN 978-1-62708-091-0.

19. Prasad, Y.V.R.K.; Seshacharyulu, T. Modeling of hot deformation for microstructural control. Int. Mater. Rev. 1998, 44, 243-258. [CrossRef]

20. Prasad, Y.V.R.K. Processing Maps-A Status Report. J. Mater. Eng. Perform. 2003, 12, 638-645. [CrossRef]

21. Ziegler, H. Some extremum principles in irreversible thermodynamics with applications to continuum mechanics. In Progress in Solid Mechanics; John Wiley: New York, NY, USA, 1965; Volume 4, pp. 91-193.

22. Prasad, Y.V.R.K.; Rao, K.P. Processing maps and rate controlling mechanisms of hot deformation of electrolytic tough pitch copper in the temperature range 300-950 ${ }^{\circ} \mathrm{C}$. Mater. Sci. Eng. A 2005, 391, 141-150. [CrossRef]

23. Grobner, J.; Schmid-Fetzer, R. Key issues in a thermodynamic Mg alloy database. Metall. Mater. Trans. A 2013, 44, 2918-2934. [CrossRef]

24. Jeong, J.; Im, J.; Song, K.; Kwon, M.; Kim, S.K.; Kang, Y.B.; Oh, S.H. Transmission electron microscopy and thermodynamic studies of CaO-added AZ31 Mg alloys. Acta Mater. 2013, 61, 3267-3277. [CrossRef]

25. Morris, J.R.; Schraff, J.; Ho, K.M.; Turner, D.E.; Ye, Y.Y.; Yoo, M.H. Prediction of a $\{1122\}$ hcp stacking fault using a modified generalized stacking-fault calculation. Philos. Mag. A 1997, 76, 1065-1077. [CrossRef]

26. Jonas, J.J.; Sellars, C.M.; Tegart, W.J.M. Strength and structure under hot working conditions. Metall. Rev. 1969, 14, 1-24. [CrossRef]

27. Frost, H.J.; Ashby, M.F. Deformation-Mechanism Maps: The Plasticity and Creep of Metals and Ceramics; Pergamon Press: Oxford, UK, 1982; p. 44. 